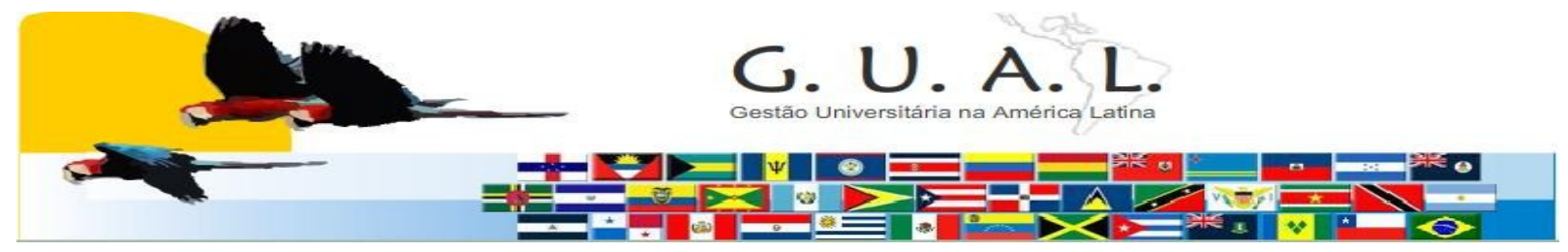

ISSN 1983-4535

\title{
ESTRATÉGIAS ACADÊMICAS E SUAS MANIFESTAÇÕES - O DISCURSO E A PRÁTICA
}

\author{
Haroldo Andriguetto Junior, Mestre \\ Pontificia Universidade Católica do Paraná - PUC \\ haroldo.andriguetto@hotmail.com
}

Victor Meyer Junior, Doutor

Pontificia Universidade Católica do Paraná - PUC

v.meyer@matrix.com.br

\author{
Lucilaine Pascucci, Doutor \\ Pontificia Universidade Católica do Paraná - PUC \\ lucilaine.pascucci@gmail.com
}

Aureo dos Santos, Doutor

Universidade do Sul de Santa Catarina - UNISUL aureods@gmail.com

\section{RESUMO}

O objetivo deste artigo é analisar as estratégias acadêmicas e sua prática, examinando a realidade de uma universidade comunitária em Santa Catarina. O estudo está fundamentado nos trabalhos de Baldridge, Cohen e March, Weick, Keller, Hardy, Langley, Mintzberg e Rose, Hardy e Fachin, Birnbaum, Mintzberg e Meyer Jr., que destacam diversos fatores que fazem das universidades organizações complexas, atípicas e com implicações em seu gerenciamento. Trata-se de um estudo de caso que teve como foco de análise estratégias acadêmicas relevantes no período de 2001-2008. Os dados foram coletados junto às seguintes fontes: dados organizacionais, observações não participantes e entrevistas com base em narrativas com cinco gestores. A análise revela a presença de estratégias acadêmicas emanadas da administração superior do tipo "guarda-chuva". As principais estratégias acadêmicas, de natureza emergente, surgem por iniciativas individuais e de pequenos grupos com a influência de aspectos racionais, políticos e simbólicos. As mais destacadas conclusões apontam para um discurso da administração superior centrado na racionalidade da gestão, privilegiando modelos empresariais incompatíveis com a realidade complexa da universidade. Revelou-se uma gestão acadêmica amadora, incremental e promotora de iniciativas estratégicas emergentes, com resultados significativos para o desempenho dos programas acadêmicos e da instituição.

Palavras-chave: Estratégia acadêmica. Complexidade. Gestão estratégica. Discurso e prática. 


\section{INTRODUÇÃO}

O cenário competitivo atual impõe desafios e pressões ambientais às organizações educacionais. Universidades não estão imunes a essas influências, em especial, relacionadas às necessidades de conhecimento emanadas do setor produtivo e da sociedade. Para se manterem atuantes precisam desenvolver estratégias que tragam resultados sustentáveis: alunos, recursos e prestígio organizacional.

Realizar a gestão estratégica em universidades é um trabalho aparentemente semelhante ao de uma organização qualquer. É necessário fixar-se em fatores críticos de sucesso: competição, demanda e custos. Tais decisões impactam diretamente em uma das áreas-chave da universidade, onde se identifica o grande diferencial e desafio de gestão: a área acadêmica e suas estratégias.

A área acadêmica é complexa e dinâmica. É formada por profissionais altamente especializados que atuam com base em sua competência profissional em um trabalho essencialmente qualitativo e individual (Mintzberg et al., 2006). Os objetivos e interesses divergem entre seus integrantes, que competem e interpretam fatos diferentemente. Além disso, ora se retraem em grupos altamente fortificados em defesa de interesses ou posições comuns, ora figuram em isolamento quase completo, agindo de maneira semiautônoma.

O objetivo deste artigo foi analisar o processo de formação de estratégias acadêmicas de uma universidade pública e comunitária de direito privado e identificar, a partir das particularidades de seu funcionamento, as causas e implicações das diferenças entre discurso e prática na gestão estratégica.

Em termos teóricos, o estudo se fundamentou na teoria estratégica em organizações, com foco especial em gestão universitária, tratando especificamente do processo de formação de estratégias em organização profíssional, com características complexas.

\section{REFERENCIAL TEÓRICO}

\subsection{A Universidade}

Universidades são organizações complexas e paradoxais cujas características são destacadas por autores como Etzioni (1972), Cohen e March (1974), Weick (1976) e Baldridge (1983). Estas organizações apresentam dinâmica interna muito particular e recebem um tipo de influência externa que particulariza sua gestão, sobretudo no que se refere à 
dinâmica entre tomada de decisão e execução de ações estratégicas. Tais características têm significativo impacto na área acadêmica.

\subsubsection{Fatores internos}

Universidades são organizações especializadas e com centros de poder divididos por área de competência profissional (Etzioni, 1972). Um dos centros de poder é representado pela administração central e outro se estabelece junto aos profissionais especialistas que compõem a universidade. A dinâmica interna das universidades, principalmente em relação ao segundo centro de poder, levou Cohen e March (1974) a cunharem a expressão "anarquia organizada" ao se referirem a estas organizações. Na visão desses mesmos autores:

Professores decidem se, quando e o que ensinar. Os alunos decidem se, quando e o que aprender. Os legisladores decidem se, quando e quem apoiar. Nem coordenação, nem controle são praticados. Os recursos são alocados por qualquer processo, emergindo constantemente, mas sem acomodação explícita e sem referência a algum objetivo superordenado. As "decisões" do sistema são uma consequência produzida pelo próprio sistema, decididamente controladas por ninguém (Cohen e March, 1974, p.33).

Em universidades, as decisões tomadas e ações desenvolvidas pelos especialistas em “atuação profissional” são frouxamente articuladas (Weick, 1976). As interações internas assumem características não lineares, imprevisíveis e conflituosas, devido aos diferentes grupos envolvidos e ao contexto pluralístico em que as interações ocorrem (Jarzabkowski e Felton, 2006). Tais características são muito similares às de um Sistema Adaptativo Complexo - SAC (Stacey, 1996), onde os agentes se identificam em grupos que compartilham interesses e expectativas, agregam-se, cooperam entre si e agem sem uma direção linear ou causal. Neste contexto, o sistema se auto-organiza e evolui.

Em universidades, assim como em SAC, qualquer tipo de previsão sobre o comportamento dos agentes será resultado de uma soma de comportamentos individuais. Os agentes, por meio de escolhas e ações individuais, definem seu comportamento e traçam seu caminho aleatoriamente, se auto-organizando a partir de padrões emergentes que se refletem no sistema como um todo (Stacey, 1996).

Transformar intenções em ações neste contexto torna-se um grande desafio aos gestores de universidades. Por tratar-se de grupo altamente profissionalizado e especializado (Mintzberg et al., 2006), determinado problema ou demanda interna pode assumir diversas 
soluções, uma vez que variam as formações profissionais, os interesses e as interpretações dos grupos internos, os quais têm autonomia. Também é comum, em universidades, que cada profissional busque adequar o problema à sua interpretação e à solução que julgue supostamente ideal (Weick, 1976). Contrariamente a sistemas justapostos, onde os objetivos são claros e se identifica uma relação de causalidade, em organizações universitárias não há uma lógica prevista e, tampouco, os eventos podem ser facilmente justificados.

Universidades são organizações atípicas e diferentes de organizações empresariais, que buscam puramente o lucro. Universidades não são como agências governamentais que procuram realizar atividades baseadas em leis, nem ainda como hospitais, que tencionam curar doentes (Baldridge, 1983). Universidades possuem objetivos duvidosos, tecnologia problemática e produto intangível. Objetivos duvidosos, pois é grande o seu âmbito de possibilidades de atuação: ensino, pesquisa, serviços de apoio à comunidade, administração de instalações científicas, incentivo às artes, soluções para problemas sociais, produção científica por parte de estudantes e professores, entre outras. Nestas organizações, a tecnologia é problemática, pois sua demanda é específica e seu "produto" é altamente intangível: o conhecimento para fins diversos e variados.

O comportamento da organização universitária desconsidera delimitações de área e, sobretudo, modelos racionalmente construídos. Na universidade, de acordo com Meyer Jr. (2007), o comportamento dos agentes não é orientado por regras e regulamentos, pelo cumprimento de modelos padronizados, por delimitações de áreas de competências e atribuições, e por estruturas hierarquizadas. As organizações universitárias tendem a ser mais fluidas, com articulações frouxas entre os diferentes grupos e centros de poder. Tais características têm reflexos significativos na forma com que estas organizações são gerenciadas, como também nos resultados das ações empreendidas (Weick, 1976; Baldridge, 1983; Meyer Jr., 2007).

\subsubsection{Fatores externos}

Universidades apresentam grande sensibilidade a fatores ambientais (Baldridge, 1983; Birnbaum, 1989). Em função de sua complexidade, a reação destas organizações a oportunidades e ameaças do ambiente é lenta, o que dificulta sua capacidade de resposta e o atendimento de demandas da sociedade. Por muito tempo estas organizações sobreviveram neste ritmo e com as limitações que ele lhes impunha. 
Nos últimos anos, porém, um novo contexto tem imposto mudanças ao setor educacional (Meyer Jr. e Murphy, 2003). As alterações no mercado de trabalho com exigências de novas habilidades e surgimento de profissões, questionamentos por parte do setor produtivo acerca da qualificação dos profissionais recém-formados e o acirramento da concorrência, que tem mercantilizado a educação superior em detrimento da qualidade, são exemplos de interferências ambientais que têm exigido medidas por parte dos gestores destas organizações.

O resultado tem sido um currículo universitário cada vez mais flexível e participativo (Meyer Jr., 2007), com implicações na gestão e reflexos em toda a comunidade acadêmica. A flexibilidade dos currículos é resultado da influência de grupos internos, como alunos, professores e colaboradores, assim como de grupos externos, representados por pais de alunos, líderes comunitários, governo, órgãos de classe, entre outros. Assim, universidades modificam a oferta de cursos, suas tecnologias e impõem novos desafios, posturas e conhecimentos ao corpo docente. Investimentos são realizados em imagem, estruturas modernas, campanhas publicitárias, os quais transformam sua essência - que deveria ser baseada no conhecimento - em "produtos" mercadológicos e de grande apelo comercial.

Há, ainda, a interferência de entidades de classe, que influenciam as estratégias acadêmicas ao influenciarem grupos da comunidade acadêmica em prol de interesses convergentes ou de "bandeiras" políticas dominantes (Baldridge, 1983). Embora a universidade seja apartidária, são históricas as manifestações políticas e as causas sociais que tiverem origem em seu contexto. Como já se destacou (Meyer Jr. e Murphy, 2003), é normal identificar, em universidades, grupos acadêmicos que ora se apresentam em isolamento quase completo, ora se mostram unidos e fortes em prol de causas de comum interesse.

\subsection{Estratégias em Universidades}

A literatura sobre estratégias em organizações é vasta, com predominância da visão clássica que pressupõe a lógica da razão sobre a ação. Tal discurso é sequenciado ao pressupor passos de uma programação estratégica que vai do pensamento à ação (Steiner e Miner, 1977; Porter, 1986).

Estudos mais recentes têm considerado as limitações da racionalidade humana (Simon, 1976), assim como também já se assume que algumas estratégias somente são percebidas depois que ocorreram - ex post facto, de acordo com uma visão retrospectiva (Weick, 1979) e 
interpretativa (Weick, 1979 e Daft e Weick, 2007). Este novo olhar sobre organizações e estratégias organizacionais permite que as primeiras sejam comparadas a sistemas interpretativos (Daft e Weick, 2007), onde ações e escolhas estratégicas passam a ser resultado da interpretação e do sentido que indivíduos dão a determinado contexto e que pode variar de pessoa para pessoa, conforme experiências, crenças, aspirações e interesses.

Neste contexto, a escolha estratégica passa a ser crucial e fator diferenciador entre organizações tradicionais e organizações complexas. Em organizações tradicionais, as escolhas estratégicas assumem uma característica justaposta, sendo associadas a recursos, demandas, produção e objetivos, estabelecendo uma relação de causalidade. Em organizações complexas como universidades, grande parte das escolhas estratégicas é conflitante e ambígua (Chakravarthy e White, 2002), já que nem todas as alternativas são conhecidas, os objetivos e as preferências são divergentes e o processo estratégico é fortemente influenciado por fatores políticos e simbólicos.

Em universidades, a escolha estratégica é fragmentada, visto que cada agente é percebido como um tomador de decisão autônomo (Cohen e March, 1974; Meyer Jr., 2007). A característica frouxamente articulada da gestão faz com que iniciativas estratégicas surjam de diferentes áreas e agentes internos, independentemente das preferências formalmente estabelecidas nos planos da alta administração. Neste contexto onde as ações são ilógicas, não lineares e em todos os sentidos (inclusive contrário), a capacidade de previsão é prejudicada e o alinhamento entre discurso e prática torna-se um grande desafio. Assim, quando muito, as ações estratégicas são gerenciadas ex post facto, quando também ocorre uma atribuição de sentido, de acordo com os objetivos e interesses da universidade. Um dos grandes desafios de gestores, como também de pesquisadores, está em reconhecer tais iniciativas e saber como surgem, se formam e se desenvolvem.

Devido à complexidade e descentralização de decisões, em universidades as estratégias podem se formar em três níveis distintos: individualmente com os professores; na estrutura administrativa e na coletividade entre os integrantes internos (Hardy et al., 1983).

As estratégias do primeiro tipo são aquelas relacionadas ao modo de ensinar de cada profissional, considerando-se que "professores decidem o que e se vão ensinar" (Cohen e March, 1974, p.33). Tal comportamento é influenciado pelos conhecimentos, competências profissionais, credos e valores que se apresentam mais fortes que as próprias influências institiucionais. Professores, como profissionais especialistas, decidem livremente sobre o 
conteúdo dos cursos, método de ensino e as intenções de pesquisa, e deste modo eles "criam padrões, levando ao que pode ser chamado de estratégias pessoais ou de professores individuais" (Hardy et al., 1983, p.424).

Estratégias originadas na estrutura administrativa são do tipo "guarda-chuva", conforme categorização de Mintzberg e Waters (1985). Tais estratégias são apenas direcionamentos gerais que permitem margens ou limites para atuação e emersão das estratégias de seus agentes. Inconscientemente ou não, a alta administração assume que a prática estratégica sofrerá influências do ambiente interno e dos agentes que o compõem. A última categoria de Hardy et al. (1983) refere-se às estratégias formadas no consenso coletivo, que resultam da interação entre áreas funcionais sendo, em geral, mais consistentes. Portanto, todo tipo de interação faz com que novas estratégias emerjam em resposta às forças ambientais das quais essas organizações são extremamente dependentes e sensíveis.

Mesmo considerando que estratégias acadêmicas emergem de níveis distintos da universidade, elas são a forma pela qual a organização se relaciona com seu ambiente externo, sendo condição para sua própria sobrevivência (Keller, 1983). Por conseguinte, estratégias acadêmicas derivam da consideração de diversos fatores internos e externos, conforme demonstrado na figura a seguir:

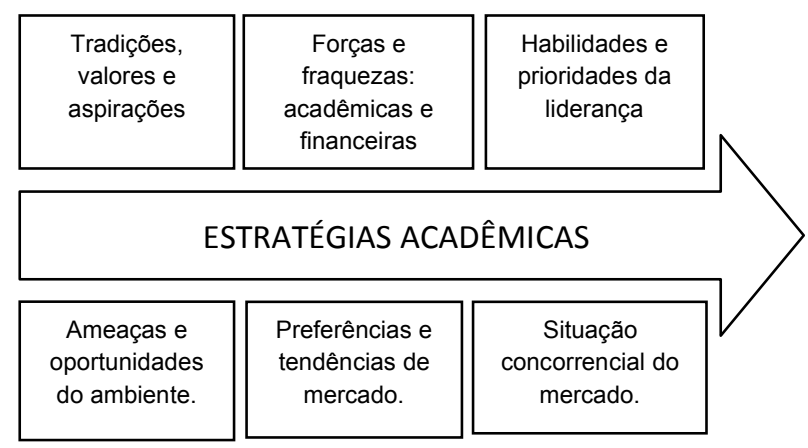

Figura 1 Estratégias acadêmicas Fonte: Keller (1983)

Portanto, como já se enfatizou, a dinamicidade interna da universidade faz com que a verdadeira estratégia acadêmica se "concentre em decisões, e não em planos documentais, análises, previsões e metas.” (Keller, 1883, p.148). Ainda segundo este autor, planos apenas orientam as ações e fornecem "antenas" para que a organização analise seu ambiente, 
enquanto muitas das ações relevantes para a universidade surgem simplesmente de interações, e por este motivo "escapam” das análises racionais do plano.

Abordagens gerenciais modeladas para a realidade empresarial têm, cada vez mais, buscado se adequar à realidade universitária, todavia, sem resultados satisfatórios (Meyer Jr., 2007). Metodologias como Balanced Scorecard, Qualidade total e Planejamento estratégico não foram criadas para atender às especificidades de universidades, como sistemas complexos que são. Trata-se de modismos da administração para se medir o imensurável - o conhecimento - e controlar o incontrolável - o comportamento dos especialistas em campo.

Em universidades não há uma única direção, lógica e deliberada para atingir objetivos e cumprir a missão institucional. A gestão estratégica em universidades assemelha-se mais a "[...] uma mistura de análises econômicas e racionais, manobras políticas e integração psicológica. É, portanto, participativa e altamente tolerante à controvérsia” (Keller, 1983, p.148). Neste contexto, há uma interação entre as dimensões política, racional e simbólica, com destaque muito mais de umas do que de outras.

\subsection{Dimensões racional, política e simbólica}

Notoriamente as dimensões racional, política e simbólica afetam a gestão estratégica das organizações, podendo variar a influência destas dimensões de organização para organização. Trabalhos de Keller (1983), Bolman e Deal (2003) e Meyer Jr. (2005), por exemplo, destacam claramente a mescla dessas dimensões e a sua influência em diferentes processos organizacionais.

Para Keller (1983), estratégias acadêmicas são resultados de análises racionais ou deliberadas, jogo político e integração psicológica. Bolman e Deal (2003) ressaltam que as dimensões são identificadas na análise de processos como o planejamento, as tomadas de decisão, mudanças estratégicas, e em mecanismos de avaliação ou retroalimentação do sistema organizacional. Tais dimensões, de acordo com Meyer Jr. (2005), servem como "lentes" para análises do planejamento universitário, que é resultado de atos racionais, políticos e simbólicos, com reflexos no desempenho da área acadêmica. A análise das estratégias acadêmicas a partir destas três dimensões evidencia implicações que o contexto externo e, especialmente, o contexto interno impõem aos gestores universitários, tornando complexa a tarefa de alinhar discurso à ação.

Rev. GUAL., Florianópolis, v. 4, n. 3, p.126-152, set/dez. 2011 
A dimensão racional está associada à visão clássica de gestão, sendo altamente difundida e predominante na gestão de muitas organizações. Trata-se de uma programação estratégica que prevê a predominância da racionalidade sobre algumas decisões. Esta visão de gestão parte de princípios racionais e lógicos, com nítida distinção entre planejamento e execução, razão e ação (Mintzberg et al., 2006), encontrada em estudos de autores como Steiner e Miner (1977), Porter (1986), entre outros.

Já a dimensão política destaca a presença de negociações, barganhas, disputas e conflitos de interesse dentro da organização. Isto ocorre porque as organizações são compostas de indivíduos que pensam diferentemente e possuem expectativas e interesses divergentes (Pfeffer e Salancik, 1974; Pettigrew, 1977; Baldridge, 1983). As diversas interpretações geram diferenças entre preferências e crenças, entre prioridades organizacionais e alocação de recursos, os quais exigem mediação e a adoção de mecanismos não burocráticos para acomodação dos interesses envolvidos nas tomadas de decisão.

A dimensão simbólica tem como foco o significado que eventos, decisões, discursos e rituais representam para a organização. Possui forte ligação com a cultura organizacional (Meyer Jr., 2005), portanto, a maneira pela qual situações são interpretadas e significadas internamente pode, inclusive, influenciar no desempenho organizacional. A própria linguagem, no dizer de Wittgeinstein (1972): o falar de recursos, mercados, ameaças e tendências compõe a "língua franca da estratégia". Tais elementos, quase sempre, são acompanhados de modelos, análises e discursos que assumem um caráter puramente simbólico, reproduzido pela organização ou pelos "estrategistas".

Whittington et al. (2003) já destacou que discursos simbólicos são identificados, em geral, em "conversas estratégicas". Fazem parte destes eventos pessoas habitualmente dotadas de poder, influência política ou elevado grau de capital cultural. Carter e Mueller (2004) destacam que o simples fato de possuir uma estratégia acarreta efeitos simbólicos. Para os autores, algumas organizações se utilizam da estratégia apenas para impressionar stakeholders ou, ainda, para a criação de mitos e cerimônias.

\section{METODOLOGIA}

Esta pesquisa é de cunho qualitativo, tratando-se de um estudo de caso (Stake, 2000) descritivo ex-post-facto, com avaliação transversal. O nível de análise foi o organizacional, e 
a unidade de análise, as estratégias acadêmicas de uma universidade comunitária localizada no sul do Brasil denominada, neste estudo, de Universidade Alfa.

O estudo de caso, na acepção de Ludke e André (1986), visa a uma descoberta a partir da interpretação de um contexto. Para Stake (2000), um estudo de caso sempre será particular, distinto e específico, pois possui um interesse próprio e singular. Neste estudo, buscou-se identificar eventuais lacunas que possam existir entre discurso e prática estratégica.

Os dados foram coletados de diversas fontes: entrevistas do tipo narrativas, observações não participantes e documentos. Adotou-se este tipo de entrevista pelo interesse de que o entrevistado relatasse livremente aspectos do conteúdo da pesquisa. Foram entrevistados cinco gestores acadêmicos de níveis organizacionais diferenciados: um da alta administração (E1), um da administração intermediária (T1) e três do nível operacional, aqui considerados coordenadores de curso $(\mathrm{O} 1, \mathrm{O} 2$, e $\mathrm{O} 3)$.

O estudo compreendeu o período de 2001 a 2008 e teve como foco as estratégias acadêmicas praticadas pela universidade. Dentre as estratégias identificadas, quatro delas foram selecionadas para estudo aprofundado. Adotaram-se como critérios de seleção a relevância do impacto no desempenho da universidade, consoante análise dos pesquisadores, e o número de vezes que tais estratégias foram citadas pelos entrevistados. Os dados foram analisados mediante técnicas de análise de narrativa (Manning e Cullum-Swan, 1994) e de análise documental (Bardin, 1977).

\subsection{Universidade Alfa}

A Universidade Alfa é uma instituição de grande representatividade no Estado de Santa Catarina. Fundada em 1964, possui atualmente cinco campi, seis unidades de ensino e aproximadamente 50 mil alunos. No ano de 2011 ofertou 61 cursos de graduação e cinco cursos de pós-graduação stricto sensu em diferentes áreas do conhecimento. Possui ainda uma variedade de programas acadêmicos oferecidos via Educação a Distância. Trata-se de uma instituição empreendedora, com grande tradição e valores reconhecidos pelas comunidades local e regional. 


\section{ANÁLISE}

No quadro 1 estão apresentadas as quatro principais estratégicas identificadas no discurso dos entrevistados e nas publicações institucionais. Tais estratégias constituem-se objetos de análises posteriores.

Quadro 1 Análise das estratégias acadêmicas.

\begin{tabular}{|c|l|l|l|l|}
\hline Estratégia acadêmica & \multicolumn{1}{|c|}{ Objetivo principal } & \multicolumn{1}{|c|}{$\begin{array}{c}\text { Processo } \\
\text { estratégico }\end{array}$} & $\begin{array}{c}\text { Dimensão } \\
\text { predominante }\end{array}$ \\
\hline EA1 & $\begin{array}{l}\text { Integração das unidades } \\
\text { acadêmicas. }\end{array}$ & $\begin{array}{l}\text { Desenvolver cursos que } \\
\text { envolvam diferentes níveis e } \\
\text { modalidades de ensino. }\end{array}$ & $\begin{array}{l}\text { Deliberada. } \\
\text { Emergente. } \\
\text { Criativa. }\end{array}$ & Política \\
\hline EA2 & $\begin{array}{l}\text { Profíssionalização da } \\
\text { gestão acadêmica. }\end{array}$ & $\begin{array}{l}\text { Transformar coordenadores em } \\
\text { gestores, cursos em UEN e } \\
\text { gestão de custos. }\end{array}$ & $\begin{array}{l}\text { Deliberada. } \\
\text { Racional. } \\
\text { Evolutiva. }\end{array}$ & Simbólica \\
\hline EA3 & $\begin{array}{l}\text { Gestão do portfólio de } \\
\text { cursos. }\end{array}$ & $\begin{array}{l}\text { Promover a Gestão de portfólio } \\
\text { por campus. }\end{array}$ & $\begin{array}{l}\text { Deliberada. } \\
\text { Racional. } \\
\text { Evolutiva. }\end{array}$ & Política \\
\hline EA4 & $\begin{array}{l}\text { Gestão estratégica de } \\
\text { curso. }\end{array}$ & $\begin{array}{l}\text { Promover a captação e retenção } \\
\text { de alunos. }\end{array}$ & $\begin{array}{l}\text { Emergente. } \\
\text { Criativa. }\end{array}$ & Política \\
\hline
\end{tabular}

Fonte: os autores.

Pode-se observar que o surgimento da estratégia EA1, focada na integração das unidades acadêmicas, partiu de iniciativa da administração central (Hardy et al., 1983) caracterizando-se como uma estratégia que segue o modelo guarda-chuva, destacado por Mintzberg e Waters (1985). No entanto, sua efetiva implementação e desdobramentos se deram por meio de um processo emergente sob a responsabilidade dos coordenadores e professores de algumas áreas acadêmicas. $\mathrm{O}$ processo emergente e as mudanças ocorreram sob a forma de processo criativo, porquanto dependiam de conhecimento, criatividade, intuição e ousadia dos gestores e professores. Um dos pontos cruciais foi conciliar as ideias dos diversos profissionais visando à integração na forma de cursos específicos. Tal dificuldade aconteceu principalmente pela diversidade de pensamentos, pela ambiguidade dos temas e pelos conflitos de interesses presentes, como destacava Baldridge (1983).

O esforço para integrar os cursos e as áreas implicou o surgimento das UNAs unidades de articulação acadêmica, que passaram a responder por um grupo de cursos e se reportaram à direção do campi. Mesmo com tal órgão, a estratégia foi fortemente marcada por conflitos e muita negociação política envolvendo as UNAs e membros das unidades acadêmicas. Acrescenta-se ainda que a entrada das UNAs encontrou forte resistência em parte 
da comunidade acadêmica. Como destacou um dos gestores acadêmicos entrevistados: "Tive forte resistência para implantar as UNAs." (relato de entrevista - E1). Tal estratégia teve como desafio (cursos integrados) a difícil missão de conciliar interesses e objetivos com professores de várias formações e áreas distintas. Os cursos definidos por tais unidades de articulação acadêmica assumiram características ascendentes ou bottom up (Minztberg e Waters, 1985).

Quanto às estratégias de profissionalização da gestão (EA2) e gestão de porfólio dos cursos (EA3), pode-se identificar que ambas assumiram características semelhantes. Tais processos resultaram de decisões da administração superior e foram efetivamente materializados seguindo um sistema integrado com características que mesclam racionalidade, política e simbolismo. A intenção da administração de implantar abordagens empresariais, como o modelo de Custeios ABC, por exemplo, dentre outros, desencadeou uma série de reações internas junto a gestores acadêmicos e professores, como resistências, desmotivação, pressão por redução de custos, ocasionando até mesmo a saída de alguns integrantes do quadro de docentes. O relato a seguir deixa claro que um dos dirigentes que estava à frente do processo de profissionalização em um dos campi teve de cancelar sua promoção por falta de apoio político, em função dos cortes capitaneados por tal líder:

Ele desistiu da candidatura porque estava mal visto perante a comunidade acadêmica. Ele fez um trabalho muito eficiente no campus, tirou gastos desnecessários de muitos cursos e centros da universidade, além de cortar muitos cursos. E com isso seu relacionamento e imagem ficaram problemáticos, sem chance de ser apoiado por alguém (Relato de entrevista E1).

Isto reforça o que já destacaram Birnbaum (1989) e Meyer Jr. (2007), que modelos desenhados e utilizados para a gestão empresarial têm pouca aplicabilidade em organizações universitárias. Neste particular, um dos gestores acadêmicos entrevistados assim se expressou: "Foi quando eu comecei a falar em negócios, que a comunidade não aceitou." (Relato de entrevista - E1). Tais estratégias envolveram análise de custos por atividade, produtividade docente, rentabilidade de cursos, margens de contribuição e retorno para a instituição. As mudanças nestas estratégias aconteceram de maneira evolutiva, à medida que os resultados eram divulgados bimestralmente em uma reunião com a gerência financeira. Esses resultados destacavam a mensuração do desempenho docente, de curso e manutenção de portfólio ou oferta no campi, que também eram negociados. Grande resistência e manifestações de cunho 
corporativista foram identificadas ao longo do processo de decisão e implantação desta estratégia.

Quanto à estratégia de profissionalização da gestão (EA2), observou-se uma clara manifestação dos aspectos político e simbólico. O primeiro em razão da intensa conversação e negociação entre as partes, e simbólico pelo entendimento de que estas novas abordagens se caracterizam mais pelo status ou aparência de gestão sofisticada do que por uma real forma de gerenciar os cursos. Esta estratégia provocou grande impacto na cultura organizacional, com resistências a indicadores de desempenho, à linguagem de negócio na área acadêmica e à gestão de custos.

No que se refere à estratégia de portfólio de curso ( EA3), pôde-se perceber que as negociações e conflitos internos entre os grupos foi predominante para viabilizar as ações estratégicas dela decorrentes. Um dos pontos em discussão foi a manutenção da oferta dos cursos ativos no atual portfólio da universidade. Observou-se que em alguns casos, como nas estratégias EA2 e EA3, mesmo tratando-se de análises racionais, algumas decisões foram balizadas por aspectos políticos. Tal fato revela que outros fatores influenciam a tomada de decisão estratégica e reforça aspectos de uma racionalidade limitada, destacada por autores como Simon (1976).

A gestão estratégica de cursos (EA4) consiste em iniciativas que surgiram na base da pirâmide organizacional, mais especificamente da área acadêmica, revelando-se, por esta razão, como "estratégia emergente". A gestão estratégica dos cursos se deu antes de tudo de maneira emergente e criativa, com ações praticadas de forma negociada, rápida, emergente e diversificada. Não se originou de análise preliminar nem tampouco de planos orientadores centrados em abordagem linear (Chaffee, 1985), onde a racionalidade, a linearidade e a relação de causa e efeito se fazem presentes. Essas iniciativas correspondem ao funcionamento de um sistema adaptativo complexo, pelas fases de identificação, agregação, interação e resultados (Meyer Jr., 2007; Pascucci e Meyer Jr., 2011).

As estratégias surgiram em movimentos independentes dos profissionais que compõem tal área (Hardy et al., 1983), eximindo-se de um padrão entre as áreas ou alguma frequência média de tempo/meta. As iniciativas simplesmente surgiram de maneira expontânea, foram legitimadas e afetaram toda a unidade, que rapidamente passou a se autoorganizar novamente, comportando-se como uma "anarquia organizada" (Cohen e March, 
1974). Pode-se identificar também que apenas em outros momentos (ditos estratégicos) foram vistas e reconhecidas algumas iniciativas retrospectivamente (Weick, 1979):

Muitas iniciativas do curso surgem da equipe e não chegam até a direção (relato de entrevista - O2). As diretrizes maiores e genéricas vêm de cima para baixo, mas no dia-a-dia, as ideias que muitas vezes fazem diferença surgem das congregações. Fizemos uma parceria que foi única na região para a oferta de cursos. Foi uma ideia nossa. Depois que deu certo, a universidade foi fazer política em cima disso e marketing para atrair alunos (relato de entrevista - O1.)

A análise das principais estratégias acadêmicas praticadas na instituição - foco do estudo - permitiu a identificação de importantes dicotomias entre o discurso dos gestores e as práticas estratégicas. O Quadro 2, a seguir, sintetiza a essência dessa dicotomia, permitindo uma interessante discussão de seus principais aspectos.

Quadro 2 Análise das estratégias acadêmicas - o discurso e a prática

\begin{tabular}{|c|c|c|}
\hline & Discurso & Prática \\
\hline EA1 & $\begin{array}{l}\text { - Cursos integrados. } \\
\text { - Maior lotação de profissionais. } \\
\text { - Formação continuada. } \\
\text { - Revisão de Projetos Pedagógicos de Cursos. } \\
\text { - UNAs. }\end{array}$ & $\begin{array}{l}\text { - Ambiguidade. } \\
\text { - Falta de consenso. } \\
\text { - Insegurança e resistência em relação aos } \\
\text { resultados da estratégia. }\end{array}$ \\
\hline EA2 & $\begin{array}{l}\text { - Formação de gestores. } \\
\text { - Unidades estratégicas de negócios. } \\
\text { - Gestão de custos. } \\
\text { - Produtividade. }\end{array}$ & $\begin{array}{l}\text { - Modelos empresariais de gestão questionados. } \\
\text { - Resistência e corporativismo. } \\
\text { - Ambiguidade. } \\
\text { - Redirecionamento em função do custo dos } \\
\text { cursos. }\end{array}$ \\
\hline EA3 & $\begin{array}{l}\text { - Atratividade. } \\
\text { - Sobrevivência. } \\
\text { - Competição e mercado. }\end{array}$ & $\begin{array}{l}\text { - Manobras políticas sobrepondo-se à } \\
\text { abordagem racional. } \\
\text { - Decisões top down inviabilizam cursos. }\end{array}$ \\
\hline EA4 & $\begin{array}{l}\text { - Prospecção de alunos, recursos e prestígio } \\
\text { para a universidade. }\end{array}$ & $\begin{array}{l}\text { - Iniciativas somente reconhecidas quando são } \\
\text { estratégicas para a universidade. } \\
\text { - Iniciativas importantes permanecem no } \\
\text { anonimato. }\end{array}$ \\
\hline
\end{tabular}

Fonte: os autores.

\subsection{EA1 - Integração das unidades acadêmicas}

O discurso é claro quanto à formação continuada, às unidades de integração acadêmica e à oportunidade de novas frentes de trabalho aos profissionais. No entanto, na prática pode-se observar uma ambiguidade sobre o que de fato representa a estratégia, o que gerou falta de consenso (Baldridge, 1983). Neste particular, o relato de um dos gestores acadêmicos de curso é claro quanto a essa ausência de clareza e de consenso: "Esta estratégia ainda é uma 
incógnita aos seus participantes, porque seu significado é divergente entre seus próprios formuladores, quem dirá seus executores" (relato de entrevista-O2).

Ficou claro ainda que alguns entrevistados apresentam insegurança em relação a essa estratégia, com visões diferenciadas advindas em geral de sua formação e experiências acumuladas em outras organizações. "Criar novos cursos pode pulverizar toda a nossa demanda e criarmos muitas opções, ao invés de concentrarmos a oferta em cursos-chave" (relato de entrevista - O3). Destaca-se também a dificuldade encontrada pelos coordenadores das UNAs ao lidarem com a forte resistência dos grupos às suas decisões e à tentativa de integrar cursos que eram independentes, ou níveis de cursos que não eram compartilhados, como o curso de Direito com Moda, por exemplo.

Ademais, observou-se grande dificuldade na comunicação de algumas decisões-chave oriundas da administração central, que privilegiaram alguns grupos e setores em detrimento de outros. O relato de um dos gestores acadêmicos entrevistados confirma essa disputa ao afirmar que: "para que um projeto vigore, primeiro temos que convencer a UNA e na minha área são nove cursos "(relato de entrevista $\mathrm{O} 1$ ).

Tal decisão sobre integração de cursos e educação permanente foi destacada por um dos entrevistados como resultante de influência externa e, mais especificamente, é uma orientação para o mercado, ao afirmar: "Em um seminário internacional de gestão universitária, um dos maiores conferencistas do mundo já falava sobre educação permanente.[...] anos depois eu implementei, é um grande negócio. É o futuro.” (relato de entrevista - E1). Trata-se de iniciativa que reforça a influência do mercado já retratada no modelo de estratégia acadêmica proposto por Keller (1983).

\subsection{EA2 - Profissionalização da gestão acadêmica}

Observou-se um descompasso entre o discurso e a prática, que se deu com destaque na forma como tal estratégia foi interpretada internamente. No discurso, previa-se que cada curso fosse visto como uma unidade estratégica de negócio, com missão, sustentabilidade e concorrentes próprios. Na prática, comprovaram-se as fraquezas financeiras que guiaram os dirigentes para uma estratégia mais "enxuta": "Havia muitos curso para se fazer uma unidade de negócio para cada curso. Ficou caro. Assim, teríamos estrutura muito grande, muito inchada e cheia de gestores." Essa estratégia e mudança de curso refletem habilidades e prioridades da liderança e forças e fraquezas financeiras propostas por Keller (1983) em seu 
modelo, como norteadoras das estratégias acadêmicas. A partir de tal decisão da administração central é que esta criou as UNAs, que apresentaram grande resistência na comunidade acadêmica. Alguns as chamavam de "fiscalizadoras".

A formação de gestores acadêmicos, conceituada como profissionalização da gestão acadêmica, foi interpretada por alguns desses gestores entrevistados como um discurso que ia contra os princípios, a tradição e a missão da universidade. Um dos gestores foi enfático ao destacar que "meu curso pode vigorar, sim, pois a universidade não precisa dar lucro" (relato de entrevista O3). Ao tentar profissionalizar a área acadêmica seguindo padrões e modelos gerenciais, todas as estratégias eram influenciadas fortemente por um orçamento com reflexos na própria universidade, sob pena de compactuar do "pacto da mediocridade", ou seja, algumas decisões não eram balizadas pela qualidade de ensino, mas por custos e metas bemvistas pela administração central. O relato a seguir deixa clara tal influência:

Existiu toda uma racionalização no sentido de que o professor vai aparecer às 4 horas dele e vai aparecer toda a parte social também como imposto de renda, previdência, etc. Então hoje você pensa duas vezes antes de solicitar autorização para contratação de um professor (Relato de entrevista - O1).

Tal decisão reflete a dimensão de forças e fraquezas financeiras do modelo de Keller (1983) influenciando as estratégias acadêmicas. O modelo advindo da realidade empresarial para gerenciar tal área foi baseado no custeio por atividade. Observou-se o equívoco de se introduzir na gestão do curso ferramentas gerenciais inadequadas que prejudicavam a essência de uma universidade: ensino, pesquisa e extensão. Tais ferramentas eram utilizadas para medir aspectos incontroláveis como produtividade docente, por exemplo. Agentes da área acadêmica eram submetidos a provisionamentos e rateio de custos que impactavam na formação de preços de seus cursos. Tais entendimentos e cobranças geraram grandes repercussões na cultura da universidade. Bolsistas do governo (Pro Uni) e da própria universidade começaram a serem questionados pelos coordenadores de curso, que não concordavam com tais "despesas" que afetavam seu orçamento.

\subsection{EA3 - Gestão estratégica do portfólio de cursos}

O discurso sobre o portfólio de cursos era descentralizado do campus acadêmico e tal decisão fazia com que os diretores de campus tivessem de decidir sobre a oferta local. Para tanto, levavam em conta aspectos de demanda, orçamento e condições dos campi. Na prática, 
notava-se que muitas decisões depunham contra orçamentos e relatórios ou balanços. Alguns cursos, mesmo deficitários, foram mantidos em alguns campi por serem importantes para o cumprimento da missão ou manutenção de uma imagem da universidade.

Ainda constatou-se que outras questões foram levadas em conta, como a oferta no período anterior (se ofertou ou não), motivação do grupo, perfil da congregação e expectativa de demanda. Em algumas situações, verificou-se que alguns cursos não eram ofertados por questões políticas internas e decisões tomadas pela direção dos campi - top down -, considerando aspectos como tradição e conceito de universidade. Tal procedimento refletia a dimensão de tradição e valores do modelo de Keller (1983). "Já colocamos relatórios e demonstramos a situação. O preço do nosso curso é alto diante da competição. Assim, perdemos alunos, mas eles não baixam. Esse semestre não ofertei curso, mas a concorrência abriu uma turma"(relatório de entrevista - O2).

\subsection{EA4 - Gestão estratégica de cursos}

As estratégias acadêmicas como as alianças, projetos e iniciativas na área acadêmica são capitaneadas pelos coordenadores de curso. Em tese, o discurso é que tais iniciativas deveriam estar alinhadas aos objetivos da universidade: missão, visão e valores. $\mathrm{O}$ que se observa na prática é um certo afrouxamento entre a filosofia da universidade e as iniciativas realizadas pelos agentes. Alguns projetos são mantidos por agentes acadêmicos durante anos, alterando-se apenas o nome ou a justificativa para atender aos requisitos da nova gestão, com poucas alterações metodológicas e práticas. Algumas iniciativas surgem de maneira "espasmódica", sem qualquer relação com algum plano. Nem todas as iniciativas chegam até as instancias superiores imediatamente. Há iniciativas que se tornam estratégicas para atender a interesses ou cumprir requisitos quando a universidade é solicitada por alguma mídia ou agente regulador externo, por exemplo.

Ficou claro que mesmo as estratégias acadêmicas sendo resultado de fatores internos e externos segundo o modelo de Keller (1983), sua formação e desenvolvimento são influenciados por características específicas da dinâmica interna da universitária, conforme demonstrado no Quadro 3. 
Quadro 3 Impacto da dinâmica interna das universidades na área acadêmica.

\begin{tabular}{|c|c|}
\hline Características organizacionais & Impacto identificado na área acadêmica \\
\hline $\begin{array}{l}\text { Ambiguidade } \\
\text { Cohen e March (1974) } \\
\text { Baldridge(1983) }\end{array}$ & $\begin{array}{l}\text { - Objetivos são interpretados de maneiras diferenciadas. } \\
\text { - Poder é ambíguo. Conhecimento acumulado x hierarquia. } \\
\text { - O sucesso é ambíguo. }\end{array}$ \\
\hline $\begin{array}{l}\text { Anarquia organizada } \\
\text { Cohen e March (1974) }\end{array}$ & $\begin{array}{l}\text { - Autonomia de ação dos agentes. } \\
\text { - Decisões de ementas, planos de ensino, parcerias, cursos. } \\
\text { - Sistema se autorregula baseado em interações. }\end{array}$ \\
\hline $\begin{array}{l}\text { Sistema frouxamente articulado } \\
\text { Weick }(1976 ; 1990)\end{array}$ & $\begin{array}{l}\text { - Iniciativas estratégicas desconexas das macrodiretrizes. } \\
\text { - Estratégias sendo reconhecidas retrospectivamente. Inversão de } \\
\text { razão-ação para ação-razão. }\end{array}$ \\
\hline $\begin{array}{l}\text { Burocracia profissional } \\
\text { Mintzberg et al. (2006) }\end{array}$ & $\begin{array}{l}\text { - Grupo com formação e especialidade diferenciadas. } \\
\text { - Interesses divergentes e conflitos de ideias. } \\
\text { - Difícil mensuração e padronização. } \\
\text { - Atuação frouxa e semiautônoma. } \\
\text { - Sensível a sistemas de controles e burocracias. }\end{array}$ \\
\hline $\begin{array}{l}\text { Estratégias em universidades } \\
\text { Hardy et al. }(1983) \\
\text { Meyer Jr. }(2005 ; 2007) \\
\text { Meyer Jr. e Walter }(2010) \\
\end{array}$ & $\begin{array}{l}\text { - Frouxamente articulada. } \\
\text { - Trabalho individualista e semiautônomo. } \\
\text { - Prática ineficiente. } \\
\text { - Carência de um modelo de gestão. }\end{array}$ \\
\hline
\end{tabular}

Fonte: os autores.

Ao analisar a dinâmica interna da área acadêmica, ficou evidente que tais iniciativas estratégicas para a universidade emergiram da interação entre seus agentes, apresentando-se em uma mescla de manifestações puramente racionais, políticas e simbólicas.

Constatou-se ainda que as estratégias acadêmicas foram iniciativas que surgiram na área acadêmica, fruto da interação basicamente entre professores, coordenadores, gestores, alunos e comunidade. As diretrizes vindas da administração central e do consenso coletivo foram apenas norteadoras do trabalho. Seu objetivo teve caráter mais simbólico - emitindo imagem de gestão planejada, organizada e profissional - do que prático.

Não se observou previsão, plano ou rotina-padrão para tais estratégias, tampouco interdependência ou integração entre os trabalhos acadêmicos (Meyer Jr. e Walter, 2010). Havia um esforço por parte dos especialistas atuantes em gerar, para cumprir fins burocráticos, o plano semestral de trabalho, contemplando suas estratégias acadêmicas. No entanto, é certo que a prática está distante de tal plano e muitas ações não são incorporadas a ele, que se perpetua por anos sem grandes reformulações: "No nosso curso pregamos tanto o planejamento e na nossa prática ele não é eficaz. Tenho acompanhado que boas iniciativas feitas por um professor, mesmo tendo resultados fantásticos, não é incorporada ao seu plano do próximo semestre."(relato de entrevista O3). 
Observa-se que estratégias acadêmicas foram influenciadas pela motivação do agente, integração com outros grupos, apoio político, criatividade, dedicação na universidade, entre outros fatores mais dependentes do próprio agente do que propriamente da universidade.

Ficou claro que nem todas as estratégias acadêmicas praticadas na base da pirâmide organizacional tiveram o consentimento da administração central ou foram por ela autorizadas e incorporadas. Foram identificados alguns heróis anônimos nesta área, ou melhor, agentes estratégicos que, por sua visão, criatividade e capacidade gerencial inovaram em sua área específica, com resultados positivos para o curso e para o desempenho da universidade.

Todas as estratégias acadêmicas analisadas e suas iniciativas posteriores foram descritas assumindo variadas justificativas: ensino, pesquisa, extensão, apoio à comunidade, missão e imagem organizacionais, dentre outras. Identificou-se que tais objetivos foram “incorporados" a estratégia de forma retrospectiva (Weick, 1979) para justificar algumas finalidades da instituição.

Quanto ao grupo acadêmico, formado por coordenadores de curso, professores e dirigentes, identificou-se que é totalmente heterogêneo e divergente quanto a opiniões, crenças e visões de mundo por apresentarem formações diferenciadas (Baldridge, 1983). Isto fez com que, na prática, um mesmo problema pudesse ter soluções variadas em razão dos níveis de complexidade de cada curso e do poder de cada unidade e gestor. Além disso, viu-se que os professores se revelaram como um grupo altamente isolado em seu trabalho de sala de aula ou produção científica, mas altamente unido em prol das causas comuns.

Observou-se ainda que muitos cargos de liderança foram ocupados por indivíduos que ocupavam a área docente ou estavam em outras posições em níveis inferiores, mas que foram elevados a cargos estratégicos. Tal fato pode desencadear uma gestão "amadora", uma vez que tais indivíduos não são especializados em gestão. Ao mesmo tempo, isso pode contribuir com a universidade para que muitas estratégias sejam legitimadas entre o grupo acadêmico, pela facilidade de acesso e discurso dentro do grupo por parte do novo líder.

Constatou-se que algumas vezes os coordenadores de curso faziam a mediação das principais diretrizes entre a administração central e os professores. $\mathrm{O}$ relato a seguir deixa clara a função política importante esperada pelo coordenador. "Os direcionamentos maiores são decididos na cúpula, com seus dirigentes. Em um determinado momento, chamamos os coordenadores também para vender a ideia aos professores. Nós somos os "filtros" entre a administração e os professores" (relato de entrevista - E1), 
Identificou-se que as estratégias acadêmicas foram mais influenciadas por informações de aspectos políticos (negociações, barganhas, troca de favores) e simbólicos (cultura organizacional, tradição e valores da universidade) do que especificamente racionais (hierarquia e regras formais).

Ficou claro que quando tais estratégias, após sua efetiva prática, foram incorporadas pela cultura organizacional, criaram um significado na comunidade acadêmica e evidências de microestratégias mais eficazes do que aquelas direcionadas de forma vaga ou ambígua pela administração central, seguindo uma abordagem top down. Nestes casos, a habilidade política e o contexto simbólico foram fundamentais. A influência das dimensões chegou a ponto de diminuir resistências, ampliar a cooperação entre os agentes, incluir novas estratégias, aumentar os esforços e a dedicação, eliminar barreiras políticas e enfraquecer o corporativismo tradicionalmente existente nessa área. Pode-se ainda observar a forte influência da variável política entre os atuais ocupantes de cargos na administração superior em busca de apoio para cargos na futura gestão. Trata-se de contribuição positiva em virtude de uma barganha que gera benefícios à área acadêmica em razão da troca de favores.

Ademais, percebeu-se que a produtividade e sua medição têm-se constituído em uma incógnita para os integrantes da área acadêmica. Na visão da administração central, tal fator esteve associado a qualquer estratégia acadêmica que agregou mais alunos, recursos e prestígio para a universidade. Acrescenta-se ainda que essas iniciativas foram reconhecidas geralmente pelo seu impacto à universidade, depois de praticadas. Já na visão dos coordenadores de curso e de alguns diretores de campi, as estratégias acadêmicas são ações grupais ou individuais que se diferenciam das comuns e que ultrapassam como foco de decisão e ação os limites da sala de aula ao mesclarem em um mesmo programa: ensino, pesquisa e extensão.

A narrativa dos entrevistados operacionais revelou que existe um gap muito grande entre a percepção de uma oportunidade ambiental e a mobilização da universidade para aproveitar tal oportunidade. Este fator foi associado à burocracia excessiva interna e à complexidade dos recursos envolvidos na geração do conhecimento específico. Os entrevistados alegaram que as decisões param em instâncias acadêmicas até serem levadas à agenda da administração superior, a quem cabe a decisão final. Nas palavras de um entrevistado: 
Algumas decisões eu tinha de tomar, porque se deixasse para a academia não saía nada. Cada coordenador acha que seu curso é melhor e mais importante [...] e da decisão final eu não abria mão porque eu sabia o que era estratégico e em quanto estavam minhas contas (relato de entrevista E1).

Além disso, identifica-se a forte presença do fator financeiro influenciando as estratégias acadêmicas com discursos e práticas: de controle de evasão, contratação de professores com impacto no orçamento do curso, bolsistas como despesas, descontos dos ingressos como despesas, laboratórios, salas, ociosidade, evasão, custos com materiais operacionais, competição externa, entre outros. Em um dos discursos, observa-se que embora sendo uma universidade pública e comunitária, mas de direito privado, sua receita é preponderante sobre as estratégias acadêmicas: "mesmo sabendo que você vai magoar determinado administrador... que vai ficar reduzido, porque não adianta, tem que apresentar resultados. E a academia é importante, mas tem que acrescentar resultados" (relato de entrevista - E1).

Ao confrontar o modelo de Keller (1983) com a prática observada na universidade Alfa, observou-se que todas as estratégias acadêmicas estavam associadas a pelo menos uma dimensão do modelo. Predominantemente, as estratégias foram influenciadas pelo contexto externo em fatores como: expectativa de uma demanda, competição local, oportunidades ambientais e parcerias. Sob o contexto interno, a tradição e os valores da universidade foram fundamentais para que as estratégias fossem implementadas com sucesso. No entanto, forças e fraquezas financeiras e acadêmicas foram balizadoras da maioria das estratégias.

Constatou-se ainda que o modelo de Keller (1983) faz suficiente referência a como as estratégias acadêmicas surgem nas universidades. Contudo, não há no modelo nenhuma dimensão que caracterize os fatores associados ao contexto em que tais estratégias estão inseridas: ambíguo, difuso, conflitante, desordenado, altamente especializado e resistente a mudanças. São fatores que acabam por influenciar as estratégias acadêmicas, independentemente da dimensão a que tal estratégia esteja vinculada.

A análise das estratégias acadêmicas destacada neste estudo revela que características internas da organização universitária, como ambiguidade de objetivos, autonomia das unidades acadêmicas (sistema frouxamente articulado), liberdade acadêmica e divergência de objetivos e interesses dos diversos grupos que compõem a estrutura acadêmica influenciaram o surgimento, o desenvolvimento e os resultados das estratégias analisadas.

Rev. GUAL., Florianópolis, v. 4, n. 3, p.126-152, set/dez. 2011 
Como exemplo, toma-se a EA1, em que se constatou que a ambiguidade e a divergência de opiniões fizeram com que a estratégia não fosse tão bem-sucedida. Esses fatores geraram insegurança em relação ao resultado da estratégia e resistência de grupos opositores. Nesta estratégica, talvez a explicação do modelo de Keller (1983) fosse de fraquezas internas ou problemas relacionados à cultura e valores. Entretanto, a natureza interna de uma universidade é, por essência, conflitante, anárquica, resistente a mudanças e, ao mesmo tempo, sensível a fatores internos e externos.

As dicotomias identificadas nas estratégias acadêmicas principalmente relacionadas a intenções e ações e entre discursos e práticas, além das influências do contexto universitário e das dimensões racional, política e simbólica, fazem da gestão universitária um verdadeiro desafio. Essas características demandam tanto esforços teóricos - na busca e fomento de pesquisas, com uma teoria própria para universidades - quanto práticos, dos pontos de vista das lideranças e dirigentes do setor, a fim de converterem tais particularidades em desempenho organizacional positivo para as universidades.

\subsection{Discussão}

A análise confirma que é inquestionável a relevância das estratégias para a gestão acadêmica de universidades. Todavia, em grande parte, a lacuna identificada entre o discurso e a prática estratégica é resultado do tratamento inadequado das especificidades da organização universitária, por parte de seus gestores e pela inexistência de uma teoria consolidada da administração universitária.

$\mathrm{O}$ estudo revelou que o setor acadêmico constitui-se em área nebulosa e ainda pouco conhecida por aqueles que a administram. De um lado, tem-se uma geração de gestores acadêmicos, normalmente ex-professores, que por razões das mais diversas são conduzidos às posições de comando de unidades acadêmicas, como responsáveis pelo trabalho de professores, pela condução de seu currículo e pela aprendizagem de gerações de alunos. Por outro lado, a falta de experiência desses professores em gestão acadêmica torna-os impotentes ou incapazes de melhor compreender a realidade complexa da área acadêmica e de buscar alternativas gerenciais para os cursos.

Pode-se observar que a tendência na universidade - foco deste estudo - é de a gestão acadêmica seguir as determinações e o discurso da administração superior, centrados em planos e metas, com ênfase na eficiência organizacional, mas baseados em modelos gerenciais 
e empresariais equivocados. Todavia, modelos gerenciais de origem empresarial, quando aplicados à gestão acadêmica, não têm sido bem-sucedidos. Seus fundamentos e premissas não se coadunam com a realidade complexa e com as especificidades das universidades identificadas na literatura. Isto tem gerado interpretações equivocadas a respeito da "produção acadêmica" e conceitos associados a sua qualidade, produtividade e formas de mensuração.

Tais fundamentos se fazem presentes no discurso da administração superior como algo estratégico, porém verifica-se que o objetivo real tem sido simbolizar uma gestão sofisticada, moderna e alinhada. Além disso, simbolizam um consenso de objetivos que não existe na prática. A observação não participante dos pesquisadores identificou que objetivos ambíguos e interesses particularísticos têm contribuído para criar conflitos entre as intenções da administração da universidade (percebidas em seu discurso) e as estratégias efetivamente praticadas na área acadêmica. Conversas e negociações têm representado o principal mecanismo para reduzir conflitos e divergências entre a administração central e os diversos grupos envolvidos na execução das estratégias.

Observou-se que algumas das estratégias praticadas derivaram de iniciativas predominantemente emergentes, com pouca ou nenhuma, ligação com os planos formais estabelecidos pela administração da universidade. As estratégias resultaram de iniciativas individuais que foram desenvolvidas paulatinamente até se tornarem padrões, e afinal consagradas em nível coletivo. Neste contexto, identificaram-se iniciativas individuais, criatividade, improviso e dedicação por parte de profisionais atuantes.

Por intermédio destes tipos de estratégia os diversos cursos, e por consequência a universidade, responderam ao ambiente competitivo em que está inserida a instituição, buscando uma diferenciação em termos de currículo, qualidade do ensino, desempenho docente e discente, maior pertinência e relevância social.

\section{CONSIDERAÇÕES FINAIS}

Há um longo caminho a percorrer na busca por uma gestão estratégica adequada à área acadêmica das universidades. As lacunas identificadas entre discurso e prática estratégica na universidade analisada evidenciam que a gestão deste tipo de organização necessita avançar além de planos e intenções.

Caracteristicas como a complexidade organizacional, o amadorismo gerencial, a ambiguidade dos objetivos, as unidades frouxamente acopladas e a natureza anárquica das 
unidades acadêmicas constituem-se em fatores limitadores para modelos gerenciais voltados à gestão estratégica em organizações acadêmicas. A gestão estratégica das unidades acadêmicas requer sobretudo arte, intuição, habilidade política. Nem sempre tais fatores parecem estar presentes nas competências dos seus gestores, o que pode comprometer seriamente o desempenho acadêmico e financeiro destas organizações.

A inexistência de uma teoria da gestão universitária consolidada certamente completa este quadro de dificuldades. Gerenciar estrategicamente organizações acadêmicas requer gerenciar o currículo, o desempenho de professores e alunos, com suas demandas individuais e coletivas. Requer adequar as atividades internas às demandas externas de uma sociedade em transformação. Certamente este constitui-se em um dos grandes desafios da universidade foco deste estudo, como também da grande maioria das universidades, o que demanda maior atenção e esforços de seus administradores e stakeholders.

\section{REFERÊNCIAS}

BALDRIDGE, J. V. Organizational characteristics of colleges and universities. In: BALDRIDGE, J. V. e DEAL, T. The dynamics of organizational change in educations. California: McCutchan Publishing Corporation, 1983.

BARDIN, L. Análise de Conteúdo. Lisboa: Edições 70, 1977.

BIRNBAUM, Robert. How Colleges Work. San Francisco, California; London: Jossey-Bass Publishers, 1989.

BOLMAN, L.G.; DEAL, T.E. Reframing Organizations: artistic, choice and leadership. $2^{\mathrm{a}}$ ed. San Francisco: Josseey-Bass Publishers, 2003.

CARTER, C.; MUELLER, F. The "long march" of the management modernizers: ritual, rhetoric and rationality. Humans Relations, v.55, n.11, 2004.

CHAKRAVARTHY, B. S.; WHITE, R. Strategy Process: Forming, Implementing and Changing Strategies. In: PETTIGREW, A.; THOMAS, H.; WHITTINGTON, R. Handbook of Strategy and Management. London: SAGE Publications, 2002.

CHAFFEE, E. Three Models of Strategy. Academy of Management Review. Vol. 10, n. 1, 1985, p. 89-98.

COHEN, M.; MARCH, J. Leadership and Ambiguity: the American College President. 2.ed. Boston: Harvard Business School Press, 1974. 
DAFT, Richard L.; WEICK, Karl E. Organizações como sistemas interpretativos: em busca de um modelo. In: CALDAS, M. P.; BERTERO, C. O. (coords.). Teoria das Organizações. São Paulo: Atlas, 2007.

ETZIONI, Amitai. Organizações Modernas. $2^{\mathrm{a}}$ ed. Tradução de Míriam L. Moreira Leite. São Paulo: Pioneira, 1972

HARDY, C.; LANGLEY, A.; MINTZBERG, H.; ROSE, J. Strategy formation in the university setting. Review of Higher Education, v. 6, n. 4, p. 407-433, Summer 1983.

KELLER, G. Academic Strategy. Baltimore: The Johns Hopkins University Press, 1983.

JARZABKOWSKI, P.; FELTON, E. Strategizing and organizing in pluralistic contexts. Long Range Planning, v. 39, p. 631-648, 2006.

LÜDKE, Menga e ANDRÉ, Marli E. D. A. Pesquisa em educação: abordagens qualitativas. São Paulo: EPU, 1986.

MANNING, P. K.; CULLUM-SWAN, B. Narrative, Content, and Semiotic Analysis. In: Denzin, N.; Lincoln, Y. Handbook of qualitative research. London: SAGE, 1994.

MEYER JR., V.; MURPHY, P. (orgs.). Dinossauros, Gazelas \& Tigres: Novas Abordagens da Administração Universitária. Um diálogo entre Brasil e Estados Unidos. $2^{\mathrm{a}}$ ed. Florianópolis: Insular, 2003.

MEYER JR., V. Planejamento Universitário: ato racional, político ou simbólico. Um estudo de universidades brasileiras. Revista Alcance, $\mathrm{n}^{\mathrm{0}}$ 12, v. 3, 2005.

A escola como organização complexa. In: EYNG, A. M; GISI, M. L. (orgs.). Políticas e Gestão da Educação Superior: desafios e perspectivas. Ijuí: Unijuí, 2007.

MEYER JR., V.; MURPHY, Patrick J. Liderança e Gestão da Educação Superior Católica nas Américas. Curitiba: Champagnat, 2007.

MEYER JR., V.; WALTER, S. A. Estratégias Acadêmicas: análises de uma escola de administração. In: SILVEIRA, A.; DOMINGUES, M. J. C. S. (coords.). Reflexões sobre Administração Universitária e Ensino Superior. Curitiba: Juruá, 2010.

MINTZBERG, H. et al. O processo da estratégia: conceitos, contextos e casos selecionados. $4^{\mathrm{a}}$ ed. Tradução de Luciana de Oliveira da Rocha. Porto Alegre: Bookman, 2006.

MINTZBERG, H.; WATERS, J. A. Of strategies, deliberate and emergent. Strategic Management Journal, n. 6, p. 257-272, 1985.

PASCUCCI, L.; MEYER JR.,V. Formação de estratégias em sistemas complexos: estudo comparativo de organizações hospitalares sob a Perspectiva Prática. In: ENANPAD: Encontro da Associação Nacional da Pós Graduação e Pesquisa em Administração, 2011. 
PETTIGREW, Andrew M. Strategy formulation as a political process. International Studies of Management \& Organization, v. 7, n. 2, p. 78-88, Summer 1977.

PORTER, M. Estratégia competitiva: técnicas para análise da indústria e da concorrência. Rio de Janeiro: Campus, 1986.

PFEFFER, Jeffrey; SALANCIK, Gerald R. Organizational decision making as a political process: the case of a university budget. Administrative Science Quarterly, v. 19, n. 2, p. 135152, Jun. 1974.

SIMON, H. A. Administrative behavior. New York: The Free Press, 1976.

STACEY, Ralph D. Complexity and Creativity in Organizations. San Francisco: BerretKoehler Publishers, 1996.

STAKE. R. E. Case studies. In: DENZIN, N. K.; LINCOLN, Y. S. (eds.) Handbook of qualitative research. London: Sage, 2000. p. 435-454.

STEINER, G. A.; MINER, J. B. Management policy and strategy - text, readings and cases. New York: McMillan Publishers Inc., 1977.

WEICK, K. E. Educational organization as loosely coupled systems. Administrative Science Quarterly, vol, 21, p.1-19, 1976.

. The social psychology of organizing. Reading. MA: Addison Wesley, 1979.

WHITTINGTON, R. et al. Taking strategy seriously: responsibility and reform for an important social practice. Journal of Management Inquiry, v.12, n. 4, p. 396-409, 2003.

WITTGEINSTEIN, L. Tractatus Logico-Philosophicus. London: Routhledge \& Kegan Paul, 1972. 


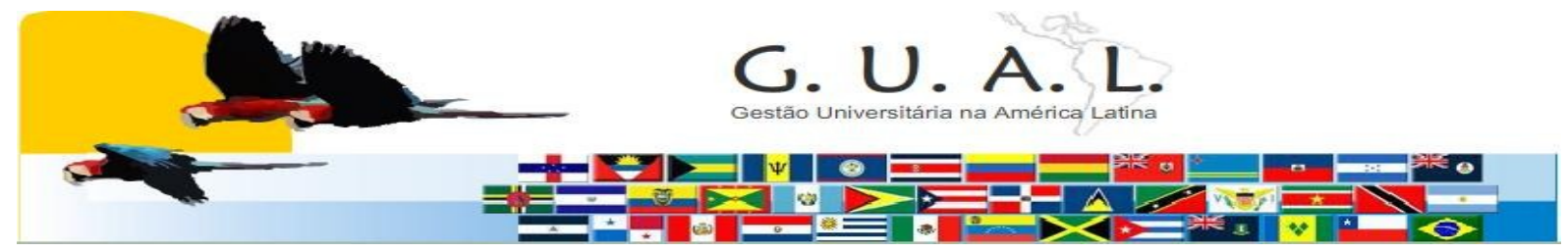

ISSN 1983-4535

\title{
ACADEMIC STRATEGIES AND EVENTS - DISCOURSE AND PRACTICE
}

\author{
Haroldo Andriguetto Junior, Master \\ Pontifícia Universidade Católica do Paraná - PUC \\ haroldo.andriguetto@hotmail.com
}

Victor Meyer Junior, Doctor

Pontificia Universidade Católica do Paraná - PUC

v.meyer@matrix.com.br

\author{
Lucilaine Pascucci, Doctor \\ Pontifícia Universidade Católica do Paraná - PUC \\ lucilaine.pascucci@gmail.com
}

Aureo dos Santos, Doctor

Universidade do Sul de Santa Catarina - UNISUL aureods@gmail.com

\begin{abstract}
The aim of this article is to analyse academic strategies and their application by examining the reality of a community University in the state of Santa Catarina. The study is based on the work of Baldridge, Cohen and March, Weick, Keller, Hardy, Langley, Mintzberg and Rose, Hardy and Fachin, Birnbaum, Mintzberg and Meyer Jr., who highlighted several factors that make the university a complex and unique organization, with implications to their management. This research is a case study which focused on the analysis of relevant academic strategies in the period of 2001-2008. Data were collected from the following sources: organizational data, no participant observation and interviews based on the narrative approach. The analysis reveals the presence of academic strategies of the "umbrella" type, coming from top administration. The main academic strategies are emergent in nature and arise as a result of individuals and groups initiatives under the influence of rational, political and symbolic factors. The main findings indicate a discourse from senior management focused on the rationality of management favoring business models incompatible with the complex reality of the university. The nature of the academic management that was revealed was amateur, incremental and one which promotes emerging strategic initiatives with significant results for the development of academic programs and the institution.
\end{abstract}

Keywords: Academic strategy. Complexity. Strategic management. Discourse and practice. 